\title{
Exploration of a New Teaching Model in College English Writing based on Production-Oriented Approach
}

\author{
Yang Yu \\ Jilin Agricultural University, Changchun, China \\ 284283440@qq.com
}

Keywords: Production-oriented approach, College English writing, Teaching model.

\begin{abstract}
The present study aims to explore a new teaching model of college English writing under the guidance of production-oriented approach. Taking non-English major freshmen of Jilin Agricultural University as research subjects, the teaching experiment is conducted through three stages---motivating, enabling and assessing. The teaching process proposed in the experiment follows "learning-using integrated principle" of POA and makes use of the discussion activity as motivators to ensure the well combination of "learning "and" using" in English writing. The results show that the new teaching model can stimulate students' enthusiasm in writing production and make the assessment more reasonable and effective.
\end{abstract}

\section{Introduction}

In order to explore the development of college English teaching in China, scholars represented by Wen Qiufang created the theoretic system "production-oriented approach (POAfor short)"[1], which is adaptive to foreign language teaching in Chinese universities. Based on Swain's "output hypothesis theory"[2], POA advocated "learning-using integrated principle", namely, "production is not only the means of motivating but teaching goals, and input is the means of enabling. The combination of input and output achieves effective teaching. The teaching process advocated by POA covers three stages: motivating, enabling and assessing in which teachers are intermediaries."[1]Presently, some university teachers begin to try to apply POA in English teaching and made progresses in teaching research. For example, Zhang Wenjuan's teaching experiment "confirms the feasibility of applying POA to college English teaching"[3]. Zhang Lingli"tested the effectiveness of POA in English teaching".[4] Sun Shuguang aims to "explore the operational principles, methods and teaching effects of teacher-student cooperation evaluation based on POA".[5] The present research intends to explore the teaching design of College English writing courses in local colleges and universities under the guidance of POA so as to promote the effective teaching of college English writing and improve students' English writing production ability.

\section{Production-oriented Approach}

Production-oriented approach is a foreign language classroom teaching theory with Chinese characteristics, which was constructed by scholars represented by Professor Wen Qiufang. POA consists of three parts: teaching concepts, teaching assumptions and teaching processes among which teaching concept is the guiding ideology, teaching assumption supports the teaching process, and teaching process is the concrete embodiment of the teaching concept and the teaching assumption. POA advocates "learning centered principle" and "learning-using integrated principle"[1].The former goes beyond the traditional models of thinking and stresses that all activities in class should be designed to achieve the teaching goal. The latter advocates that all language teaching activities should be closely related to the use of language so as to remove the boundary between "learning" and "using". "The teaching process of POA contains three main stages: 
motivating, enabling and assessing."[1]Motivating paves the way for students to have a slight knowledge of the teaching contents, in the meantime, by the process of presenting the communication scene---students trying to produce---illustrating the production task, POA could make students be aware of the difficulty of task completion so as to stimulate students' learning enthusiasm. In the enabling process, teachers provide the students with the necessary input materials, and give instruction and examination to the students' selective learning. In the assessing process, teachers need to make a timely evaluation of the students' learning effect and carry out remedial teaching, and give students a delayed evaluation of the work after the instruction.

\section{Construction of Teaching Model of College English Writing}

Firstly, POA advocates that production task should serve as a starting point for teaching. "In the traditional writing class, teachers usually organize some warm-up or lead-in activities when involving a new writing task in order to stimulate the students' interest in new content or activate the students' background knowledge."[6] In this sense, such "warming up" activities are intended to help students better accept input rather than stimulating their writing production. According to POA, the process should be reversed in the writing class. Teachers should assign the writing task in the first place and then provide students input materials and illustrate the writing structure and language usage. In POA, the "motivating" process includes: "teachers present communicative situations to students who try to complete communicative activities and teachers illustrate teaching goals and production tasks."[1] According to this feature, the present study proposes that in the course of English writing, teachers can present real communicative situations, such as participating in discussion, solving a problem in social life, expressing personal life perception and so on. Then teachers ask the students to try to complete these activities. These activities should be challengeable, e.g. many students try to provide more evidence in the discussion, but they have not enough vocabularies to express themselves and are lacking in English knowledge. Through the above activities, the students could be more conscious of their problems in language learning and the strong desire for language learning can be stimulated. Then, the teacher sets up the writing task for the students, and at the same time puts forward the learning goal, that is, the vocabulary, grammar, and related writing knowledge needed for the above communicative activities.

Secondly, POA advocates that when students encounter difficulties in expressing themselves in enabling stage, teachers should provide appropriate input materials in a timely manner, and guide students to selectively study the input materials according to the needs of production. In the teaching process of English writing, the input materials provided by the teachers should be in line with the students' English proficiency so that students can easily imitate and at the same time meet the needs of students' English expression. Therefore, the excellent compositions of our school or the students in this class, as well as the articles published in English newspapers and magazines in China, are good input materials. Students may not know what is the exact learning content at the beginning of selective learning. Teachers need to play a role in providing scaffolding through the analysis of model essays and brief explanation so as to help students learn the writing structure and language expression.

Finally, the assessing in POA includes two categories: immediate and delayed assessing. "Immediate assessing" refers to the "examination" section in the "enabling" process, that is, "the evaluation of students' learning effectiveness in the course of selective learning and production task."[7]In the English writing course, immediate assessment is mainly the evaluation of students' sentence production in the class. Delayed assessing is the evaluation provided by teacher or teacher-student cooperation on the submitted composition. The main objectiveness of the immediate assessing is to help students identify the problems in the writing structure and guide them to write coherently. According to POA, "delayed assessing means that both teachers and students study evaluation standard and participate in evaluation of composition in and after class, which makes up for the deficiencies of teacher feedback and peer review".[7] 


\section{Experiment of the New Teaching Model}

Participants. In this study, 154 non English major students were selected from three paralleled classes at Jilin Agricultural University. The students, including 85 boys and 69 girls, are all freshmen majoring in agronomy, resources and mechanical engineering. They all have six years of English learning experience and are taught by the same English teacher with the same course.

Teaching Content. This section explores how to apply POA theory to a specific case in College English writing teaching. The textbook we used was New Century College English Writing Course 3[8]. The teaching content is Unit 4 "Living Creatures". The topic of this unit is"how to write a comparison and contrast composition. The following teaching steps are designed based on POA and implemented in class.

Teaching Procedure. Firstly, the teacher assigns the task "compare and contrast two figures: Bill Gates and Steve Jobs".In accordance with the established groupings of each class, the students are asked to discuss with their group members. After the group discussion, each team leader goes to the platform to sum up their argument. The teacher visits the class during the group discussion and knows the difficulties they encounter and gives them guidance in a timely manner, and asks the students to write down the difficult expression they have encountered. At the end of the class discussion, the teacher makes an immediate comment including the comparative structure, content and language. At the same time the teacher requires the students to watch micro-class related with the discussion topic prepared in advance.

In the second stage, the teacher assigns writing tasks and explains writing knowledge. The unit requires students to write a composition with the topic of "different ways of expression between men and women". They need to have a clear point of view, sufficient evidence and idiomatic language. Because both the writing task and discussion topic are comparing and contrasting the similarities and differences between two things, the teacher's class explanation can be aimed at the difficulty which the student meets in the discussion. The main problems in the discussion are the insufficient arguments and the expression of chinglish. In addition, in writing, students are not sufficiently aware of the importance of conjunctions and subject sentence in articles and paragraphs because they rarely consider from the reader's point of view. So when illustrating, teacher focuses on the structure of two writing patterns: "point by point pattern" and "subject by subject pattern". Through the examples of cats and dogs in the text. In terms of language, the teacher introduces some necessary connection words and carries out related exercises.

In the following stage, teacher provides input materials for students to study selectively. The teacher selects an article entitled "Do men and women talk differently?"from the book English Thinking---Reading Critically 1[9] as input material. This article is relevant to the topic, and contains many practical expressions. In addition, some critical thinking models in this article can give insights to the students. It is difficult for many students to give specific examples to support their opinions. Therefore, the teacher asks students to search for materials related with the differences between men and women' talking in English websites and newspapers, and report them in class after summarizing. The input of these materials not only provides students with rich writing materials, but also improves their language expression.

According to the structure of the composition provided by teacher, students write the first draft in several steps. The students are asked to determine the comparative method ("point by point pattern" or "subject by subject pattern"[8]) first and then the content of comparison. In the class, the teacher evaluates the two tasks one by one. After that, the students are required to complete the first draft. After the completion of the first draft, the teacher explains the specific evaluation criteria and evaluates model essay. Students are required to peer review according to the evaluation criteria after class. The evaluation criteria are summarized from the question lists in the text book, such as whether the evidence is sufficient, whether the grammar is correct and whether the expression is idiomatic. As for students' language mistakes, teacher designs some exercises and practice in class. Teacher revises and gives feedback in time for each student's first draft. For the second draft, the teacher displays excellent pieces of work in class. It is difficult to read all the compositions in the limited time of class. Teacher shows some excellent sentences and paragraphs in class, which could 
stimulate students' writing enthusiasm.

In the exploration of the classroom teaching, the present study applies POA to the writing teaching design in the university. The teacher designs writing tasks and guides students to selectively learn input materials under the guidance of "learning-using integrated principle". The combination of reading and writing promotes the final completion of writing production. The teaching model guided by POA improves classroom teaching effects: the teaching goal is more clear, the classroom activities are more abundant and the classroom atmosphere is more active. After teaching experiment, the teacher interviewed the students and found that the students also showed great enthusiasm for the new teaching model.

\section{Conclusion}

Under the guidance of the theory of POA, the present study constructs a new teaching model of writing course from three aspects of input, output and evaluation and carries out the teaching experiment. Several important teaching suggestions are put forward. Firstly, the input of knowledge is no longer intended to simply enhance the students' comprehension ability , but to serve for writing production. Input should be arranged after the first production of writing or discussion. Teacher should direct the students to learn the input materials selectively. Secondly, complete teaching process includes at least two individual productions: in-class and after-class production. Thirdly, immediate assessing is presented in a variety of ways including teacher feedback and collaborative feedback. The teacher is in the lead of delayed assessing. He makes full use of students' model essays and guide students to find ways to revise the composition by themselves. This paper discusses how the theory of POA is applied to the teaching of writing courses. However, there are fewer writing classes for students. Therefore, in the future teaching, teachers could direct the students to write in the intensive and extensive reading class so as to encourage students to apply the knowledge to his writing production practice after reading.

\section{References}

[1] Q.F. Wen. Developing a theoretical system of production-oriented approach in language teaching [J]. Foreign Language Teaching and Research, 2015(4):547-558.

[2] Swain, M. Three functions of output in second language learning[A]. In G. Cook \& B. Scidlhofcr (eds.).Principles and Practice in Applied Linguistics: Studies in Humor of H.G. Widdowson [C]. Oxford: OUP. 1995. pp.125-144.

[3] W.J. Zhang. Applying Production-oriented Approach to College English Classroos: A Teaching Experiment [J]. Foreign Languages and Their Teaching, 2016(2):106-114.

[4] L.L. Zhang. An experimental study on the effectiveness of the production-oriented approach[J]. Modern Foreign Languages,2017(3):369-376.

[5] S.G.Sun. Teacher-student collaborative assessment in classroom teaching: A reflective practice [J]. Modern Foreign Languages, 2017 (3): 397-406.

[6] G.M. Jia. Application of POA in English Writing Teaching [J]. Crazy English PRO, 2016 (4): 30-32.

[7] Q.F. Wen. Teacher-Student Collaborative Assessment---a new method of assessment based on POA[J]. Foreign Language World, 2016 (5):37-430.

[8] H.P. Liu. New Century College English Writing as Communication 3 [M] Shanghai Foreign Language Education Press, 2014: 84-111.

[9] Y.Z. Sun. English Thinking---Reading Critically 1 [M] Foreign Language Teaching and Research Press, 2015: 258-265. 